\title{
Odontogenic myxoma: a clinicopathological study in a South African population
}

\author{
Fadi Titinchi $^{1}$, Bassam A. Hassan ${ }^{2}$, Jean A. Morkel $^{1}$, Christoffel Nortje ${ }^{3}$ \\ ${ }^{1}$ Department of Maxillo-Facial and Oral Surgery, Faculty of Dentistry, University of the Western Cape, Cape Town, South Africa; \\ ${ }^{2}$ Department of Oral Implantology and Prosthetic Dentistry, Academic Centre for Dentistry Amsterdam (ACTA), Amsterdam, \\ The Netherlands; ${ }^{3}$ Department of Diagnostics and Radiology, Faculty of Dentistry, University of the Western Cape, Cape Town, \\ South Africa
}

\begin{abstract}
BACKGROUND: Odontogenic myxoma is a benign, locally aggressive neoplasm of the jaws. Prevalence rates range between $\mathbf{0 . 5 \%}$ and $\mathbf{1 7 . 7 \%}$ of odontogenic tumours. There are few reports in the literature on this lesion in African populations, and therefore, this study aimed to report on odontogenic myxoma in a South African population over a 40 -year period.

METHODS: The clinical records and orthopantomograms of $\mathbf{2 9}$ histopathologically diagnosed odontogenic myxoma were retrospectively analysed. Details of age, gender, ethnic origin and clinical, histological as well as radiological features were recorded.
\end{abstract}

RESULTS: The ages of patients ranged from 7 to 44 years with a mean of 21.3 years. The male-to-female ratio was I:2.6 with the majority of patients being of mixed race and Africans. Clinically, $31 \%$ complained of pain while $58.6 \%$ had a history of swelling. The majority of odongenic myxomas (62.1\%) were located in the mandible with the posterior region being most commonly affected. Multilocular lesions (69.2\%) were more common and were significantly larger than unilocular lesions $(P<\mathbf{0 . 0 5})$. The outline of these tumours was mostly well-defined (84.6\%) with different degrees of cortication. Only one tumour caused tooth resorption, while 20 cases $(76.9 \%)$ caused tooth displacement. Six tumours expanded into the maxillary sinus, and 14 tumours caused expansion of the mandible.

CONCLUSIONS: Odontogenic myxomas have variable clinical, radiological and histological features. Most of these features in this population were similar to other populations. It is mandatory to use conventional radio-

Correspondence: Dr. Fadi Titinchi, MSc Student, Department of MaxilloFacial and Oral Surgery, Faculty of Dentistry, University of the Western Cape, Cape Town, South Africa. Tel: +27 71 3708668, Fax: +27 21959 3055, E-mail: ftitinchi@gmail.com

and

Dr. Bassam Hassan, Assistant Professor and Clinical Research Coordinator, Department of Oral Implantology and Prosthetic Dentistry, Academic Centre for Dentistry Amsterdam (ACTA), Amsterdam, The Netherlands. Tel: +31622730007, Fax: +310205188480, E-mail: b.hassan@acta.nl Accepted for publication December 15, 2015 graphs along with histopathological examination to aid in arriving at an accurate diagnosis.

J Oral Pathol Med (2016) 45: 599-604

Keywords: odontogenic myxoma; panoramic radiograph; South Africa

\section{Introduction}

Odontogenic myxoma is a benign, locally aggressive neoplasm of the jaws that was first described in 1947 by Thoma and Goldman (1). Its origin is uncertain but is believed to arise from the mesenchyme of dental papilla (2). Prevalence rates of odontogenic myxomas ranges between $0.5 \%$ and $17.7 \%$ of odontogenic tumours in Europe, Asia and America (3-5). In Africa, the tumour is slightly more common with prevalence rates ranging between $6.5 \%$ and $19 \%(6,7)$. Several studies on the incidence of odontogenic tumours have reported that odontogenic myxoma is the second most frequent tumour following ameloblastoma $(8,9)$.

There are only few reports in the literature accounting for the clinical and radiographic aspects of odontogenic myxomas, and most of these studies have reported on low number of cases. The aim of this study was, therefore, to retrospectively analyse the clinical and radiological features of odontogenic myxomas presenting in a sample of 29 South African patients over a period of 40 years and to compare the results with the current literature.

\section{Material and methods}

Data collection

Clinical records, radiographs and histological reports of 29 patients with the diagnosis of odontogenic myxoma were retrospectively reviewed. Ethical approval was granted by the senate research committee of the University of the Western Cape prior to conducting the study. The cases were selected from 35 histopathologically verified odontogenic 
myxoma presenting at Tygerberg Academic complex in Cape Town, South Africa, during the period 1971-2011. Inclusion criteria were the presence of a clinical history and at least one orthopantogram (OPG). Six cases were excluded from the study due to incomplete patient data. Details of the age, gender, ethnic origin, clinical history, histological findings as well as radiological views were obtained from each patient's file. The clinical information that was recorded included the period of time that the tumour was noted and the presence of accompanying symptoms such as pain and swelling. Radiological features that were recorded on the OPGs included site, size, shape, outline and its effects on adjacent structures including tooth resorption, tooth displacement, expansion in the maxillary sinus or mandible.

\section{Data analysis}

All radiographs were digitized using a flat bed transparency scanner (V750 PRO; Epson, Long Beach, CA, USA). The digitized radiographs were reviewed using Emago software (version 5.7; Oral Diagnostic Systems, Amsterdam, the Netherlands). The radiographs were independently reviewed by two maxillofacial radiologists. To ascertain the site of a lesion, the mandible was divided into five regions, which were the mandibular anterior region, the premolar and molar region, the angle of the mandible, body of the ramus and condylar region. The maxilla was divided into three regions namely the maxillary anterior region, the premolar and molar region and the maxillary tuberosity region.

Lesion size was measured in millimetres along the longest vertical and horizontal axis of the lesion to determine the maximal extent of tumour growth. The shape of the lesions was classified as either unilocular or multilocular whereby unilocular lesions have a single radiolucent cavity and multilocular when septa divided the lesion into two or more separate compartments giving it a 'honeycomb' or 'soap bubble' appearance. The lesion outlines were recorded as either well defined with uniform cortication, well defined with variable cortication, well defined with no cortication or ill defined. The effects of the tumour on adjacent structures were also recorded. These included tooth resorption, tooth displacement, expansion of the tumour into the maxillary sinus and bucco-lingual expansion of the mandibular cortex. Lesions that were difficult to identify due to their extensive nature were classified as non-diagnosable.

\section{Statistical analysis}

Statistical analysis included the calculation of means of different variables and correlating an association between them. The data were analysed using SPSS package (14.0, SPSS Inc., Chicago, IL, USA) to calculate means, percentages and correlations. Findings were considered statistically significant at a level of 0.05 or less.

\section{Results}

A total of 35 cases were observed over a period of 40 years at Tygerberg Academic complex in Cape Town, South Africa. Twenty-nine cases had complete clinical, radiographic and histological details and were reviewed in this study.

\section{Demographic data}

The distribution of odontogenic myxomas by age and gender is shown in Fig. 1. The ages of patients at the time of diagnosis of odontogenic myxomas ranged from 7 to 44 years with a mean of 21.3 years. The majority of tumours occurred in patients between the ages of 20 and 29 years $(37.9 \%)$. Females were more commonly affected with a male-to-female ratio of 1:2.6. Analysis of the ethnic origins of patients indicated that mixed race patients were most affected (51.8\%), followed by Africans (41.4\%) and Caucasians $(6.8 \%)$.

\section{Clinical presentation}

With regard to the clinical history, most patients complained of either having pain $(31 \%)$ or history of swelling (58.6\%) in the affected area (Fig. 2). The mean period of symptoms was 2.4 years before a diagnosis was made.

\section{Radiographic presentation}

The site of odontogenic myxomas is shown in Fig. 3. Eighteen myxomas $(62.1 \%)$ were located in the mandible, while $11(37.9 \%)$ were located in the maxilla. Twelve mandibular myxomas $(66.7 \%)$ were located in the posterior region of the mandible with some extending to the angle and ramus regions. Two myxomas involved the mandibular condyle, one of which extended from the anterior region to the condyle and coronoid process. Five further mandibular tumours occurred in the anterior and posterior regions and crossed the midline (Fig. 4). No myxomas occurred in the maxillary anterior region.

The relationship between size of odontogenic myxomas and their site and shape was analysed. The size of unilocular lesions ranged from 25 to $79 \mathrm{~mm}$ (mean $46.1 \mathrm{~mm}$ ), whereas for multilocular lesions, the size ranged from 20 to $180 \mathrm{~mm}$ (mean, $71.2 \mathrm{~mm}$ ). The mean size of multilocular myxomas was significantly greater than that of unilocular myxomas $(t$-test; $P=0.0203)$. Fourteen of the $18(77.7 \%)$ mandibular myxomas and four of the $11(36.4 \%)$ maxillary myxomas were multilocular in appearance. On the other hand, only three $(16.7 \%)$ mandibular and five $(45.5 \%)$ maxillary myxomas were unilocular in appearance. Thus, this indicates the high occurrence of multilocular myxomas in the

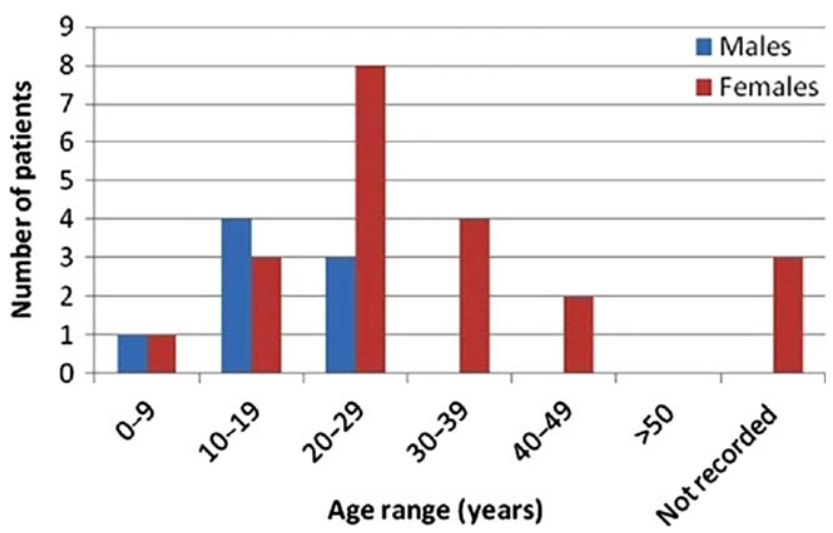

Figure 1 Graph showing age and gender distribution of odontogenic myxomas. 


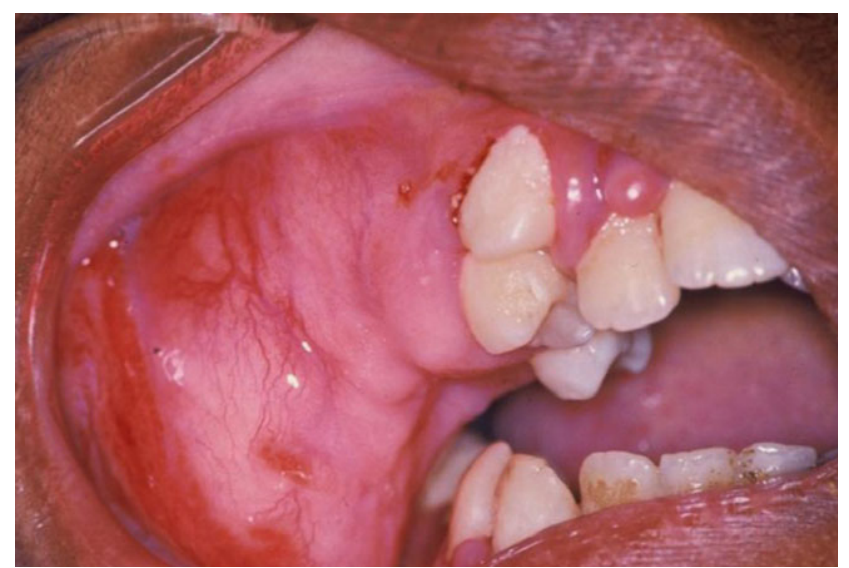

Figure 2 Clinical photograph showing marked swelling due to odontogenic myxoma.

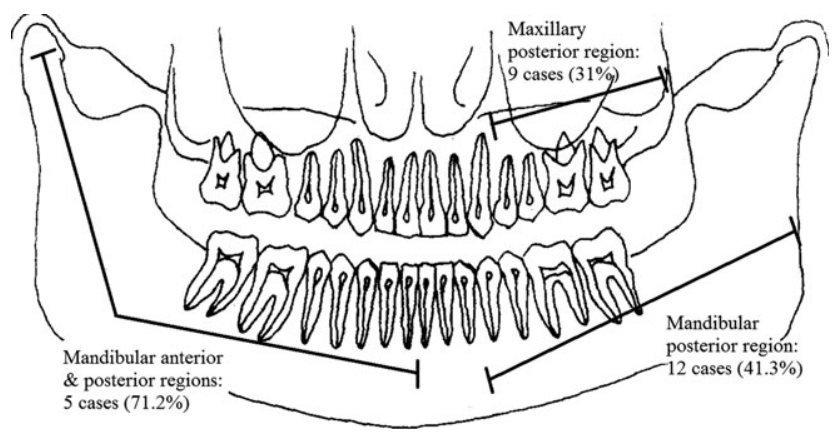

Figure 3 Schematic drawing of distribution of odontogenic myxoma in the jaws.

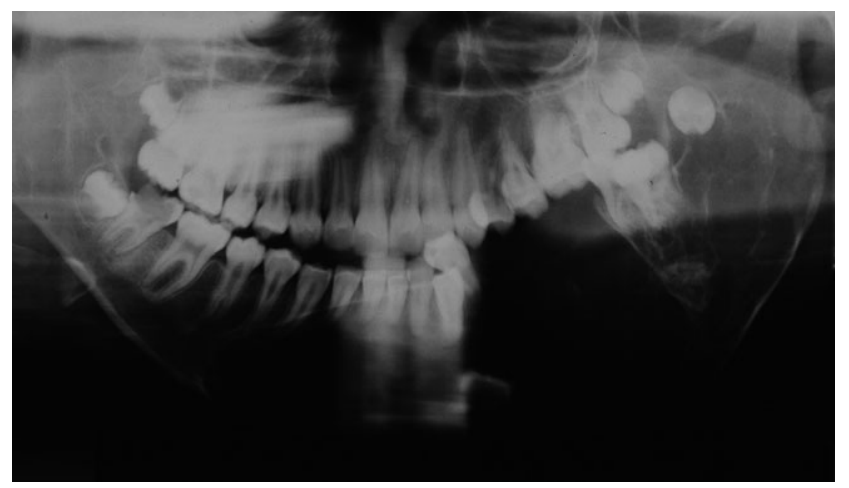

Figure 4 Pantomogram showing extensive mandibular myxoma involving the posterior regions and crossing the midline.

mandible (Fig. 5) although this finding was not statistically significant. The outline of odontogenic myxomas is shown in Table 1. There were four myxomas that had an ill-defined outline, three of which were located in the maxilla (Fig. 6).

Interestingly, only one (3.8\%) myxoma had caused tooth resorption, which extended from the premolar region to the ramus. Fourteen (77.7\%) mandibular myxomas and six (54.5\%) maxillary myxomas caused tooth displacement. Fourteen (77.7\%) mandibular myxomas caused buccolingual expansion of the mandible, while six expanded into the maxillary sinus.

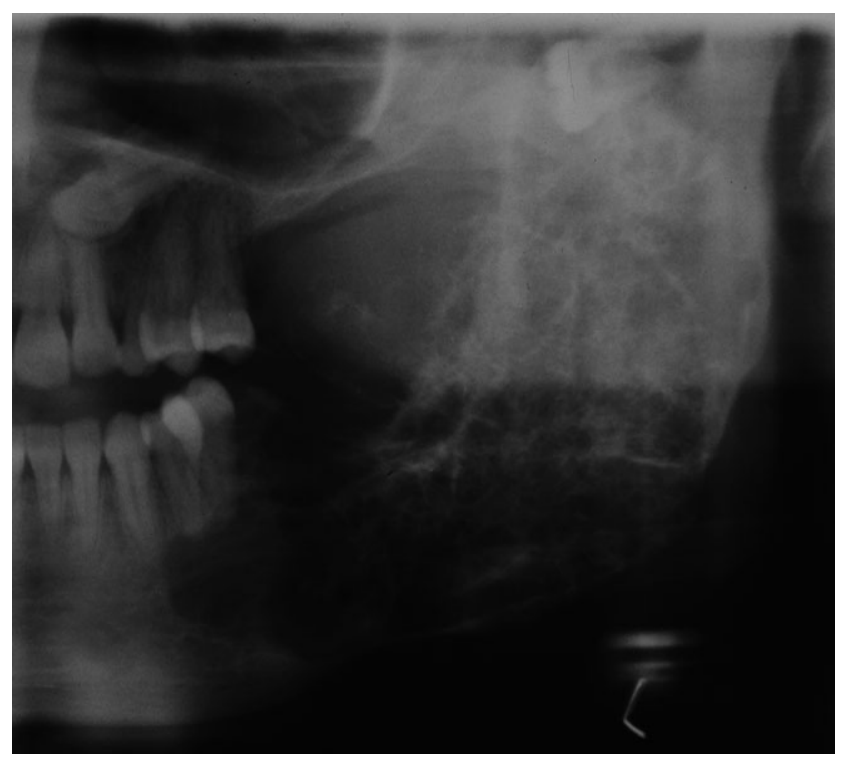

Figure 5 Pantomogram showing multilocular odontogenic myxoma in the mandibular posterior region showing the honeycomb appearance.

\section{Histological findings}

Histologically, all odontogenic myxomas in this series consisted of stellate to spindle-shaped cells in an intercellular matrix rich in mucoid (Fig. 7). Most tumours in this sample were hypocellular and monotonous with multiple cytoplasmic processes that were frequently long and joined with other cell processes. These finding were in accordance with description of this lesion by the World Health Organisation.

Most lesions showed single centrally located hyperchromatic nuclei that lie in a mucinous matrix. However, 12 cases $(41.37 \%)$ in this sample showed binucleated cells while mitosis and multinucleation were rare in this sample.

All lesions in this sample showed no sign of encapsulation and sporadically scattered residual bony trabeculae were present in 13 lesions (44.8\%). Odontogenic epithelial rests were rare and only present in two cases (6.9\%). Most lesions show minimal signs of increased vascularity, while the amount of fibrous tissue differed widely in each specimen.

\section{Discussion}

The clinical and radiographic data presented on odontogenic myxomas in this study are distinct in that there are very few reports with such a large number of cases in the literature reporting on these features. Most previous reports have studied odontogenic myxomas as part of extensive epidemiological reviews of odontogenic tumours in general and did not focus solely on odontogenic myxomas.

The majority of cases studied in this sample were diagnosed in the third decade of life (37.9\%) with a mean age of 21.3 years. This finding was similar to other reports which generally agree that the tumour rarely presents in the first decade of life and in patients above 40 years of age (8, 10). Simon et al. (8) and Noffke et al. (11), who both studied odontogenic myxomas in African populations, reported similar findings. A few case studies have reported on myxomas in patients less than 10 years of age (12). In 
Table 1 Distribution of odontogenic myxomas in the mandible and maxilla

\begin{tabular}{|c|c|c|c|}
\hline \multicolumn{2}{|l|}{ Mandible } & \multicolumn{2}{|c|}{ Maxilla } \\
\hline Site & $\begin{array}{c}\text { Number of } \\
\text { tumours }\end{array}$ & Site & $\begin{array}{c}\text { Number of } \\
\text { tumours }\end{array}$ \\
\hline Anterior region & 0 & Anterior region & 0 \\
\hline $\begin{array}{l}\text { Posterior region } \\
\text { (including ramus } \\
\text { and condyle) }\end{array}$ & 12 & $\begin{array}{l}\text { Posterior region } \\
\text { (including } \\
\text { tuberosity) }\end{array}$ & 9 \\
\hline $\begin{array}{l}\text { Anterior and } \\
\text { posterior regions }\end{array}$ & 5 & $\begin{array}{l}\text { Anterior and } \\
\text { posterior } \\
\text { regions }\end{array}$ & 0 \\
\hline Not diagnosable & 1 & Not diagnosable & 2 \\
\hline Total & 18 & & 11 \\
\hline
\end{tabular}

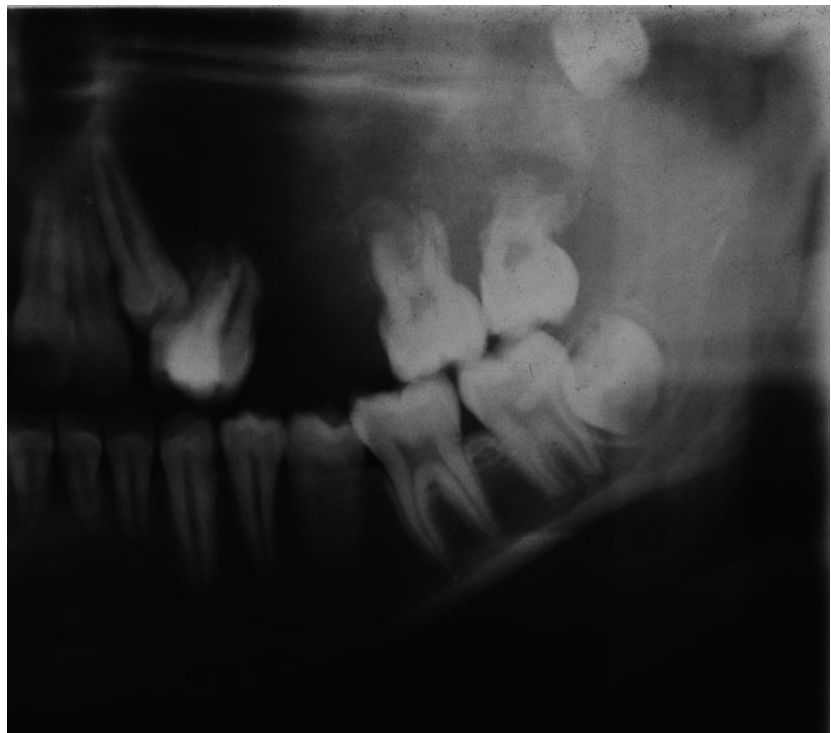

Figure 6 Pantomogram showing odontogenic myxoma in the maxillary posterior region showing ill-defined margins and ground glass appearance.

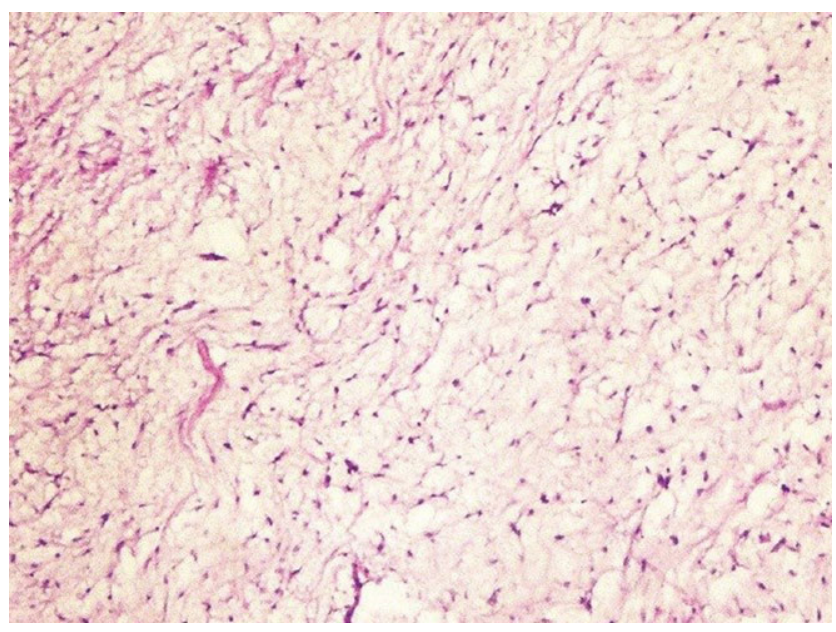

Figure 7 H \& E-stained light microscopy slide showing typical appearance of odontogenic myxoma with loosely arranged stellate-shaped cells in mucoid. our sample, two (6.9\%) patients were below 10 years of age at the time of diagnosis.

Substantial evidence in the literature demonstrates a similar gender distribution between males and females for the tumour $(6,13)$. However, some studies report a slight female predilection in their series of cases $(3,7,10)$. In our sample, there was a considerably higher frequency of myxomas in females, which were also reported by other studies in African populations including the study by Noffke et al. (11) which was conducted in a South African population. This finding may indicate that there is a higher frequency of the tumour in African females.

Most common clinical characteristics of odontogenic myxoma are swelling of the jaws with only few patients complaining of pain, paraesthesia and ulceration $(8,14)$. In our sample, $31 \%$ of patients complained of pain, while $58.6 \%$ complained of swelling in the affected area. These findings are very similar to global trends, $28 \%$ for pain and $56 \%$ for swelling, which were reported in the sole systematic review on odontogenic myxomas by MacDonald-Jankowski et al. (14). The mean period of time when these symptoms were first noted was 2.4 years. Inadequate access to healthcare facilities, low socio-economic status and lack of knowledge were key factors that contributed to late reporting of the tumour by patients. Most odontogenic myxomas are slow growing; however, reports in the literature exist of rapidly growing myxomas (15). In our sample, two myxomas were rapidly growing one of which occurred in a 12-year-old male.

With regard to tumour site, the literature is variable with several studies indicating that there is a higher rate of tumour incidence in the mandible than the maxilla $(7,8,11$, 16). In this sample, this was the case with the majority of myxomas located in the mandible $(62.1 \%)$ with the posterior regions most commonly affected. Noffke et al. (11) also reported a very similar finding in their South African sample. Other reports indicate an equal rate of incidence in the maxilla and mandible $(4,13)$. No tumour was located exclusively in the mandibular or maxillary anterior regions; however, five extensive mandibular lesions involved the anterior region and crossed the midline. A similar finding was also reported by Noffke et al. (11). Table 2 summarizes the clinical and radiological findings from previous reports and compares it to the current sample.

Radiographically, odontogenic myxomas can manifest as unilocular or multilocular radiolucencies with a wide range of sizes (15). In this study, it was demonstrated that multilocular tumours were significantly $(P<0.05)$ larger than their unilocular counterparts. Furthermore, the majority of unilocular lesions occurred in the maxilla, while the majority of multilocular lesions occurred in the mandible. This was also reported by Noffke et al. (11) which reported that the mean size of unilocular lesions was significantly less than that of multilocular lesions.

Multilocular lesions are described as having a 'honeycomb', 'soap bubble' or 'tennis racket' appearance (1). In the present sample, the honeycomb and soap bubble appearances were noticed. This was also reported by Noffke et al. (11) in their South African sample. The outline of multilocular tumours has been described as well-defined corticated, well-defined non-corticated or poorly defined 


\begin{tabular}{|c|c|c|c|c|c|c|c|c|c|c|c|}
\hline Feature & $\begin{array}{l}\text { This } \\
\text { study }\end{array}$ & $\begin{array}{l}\text { Friedrich } \\
\text { et al. (18) }\end{array}$ & $\begin{array}{l}\text { MacDonald- } \\
\text { Jankowsky } \\
\text { et al. (14) }\end{array}$ & $\begin{array}{l}\text { Martínez- } \\
\text { Mata } \\
\text { et al. (17) }\end{array}$ & $\begin{array}{c}\text { Noffke } \\
\text { et al. (11) }\end{array}$ & $\begin{array}{l}\text { Li et al. } \\
\text { (13) }\end{array}$ & $\begin{array}{l}\text { Simon } \\
\text { et al. }(8)\end{array}$ & $\begin{array}{l}\text { Lo Muzio } \\
\text { et al. (10) }\end{array}$ & $\begin{array}{l}\text { Peltola } \\
\text { et al. (16) }\end{array}$ & $\begin{array}{l}\text { Dezotti } \\
\text { et al. (19) }\end{array}$ & $\begin{array}{l}\text { White } \\
\text { and } \\
\text { Pharoah } \\
\text { (20) }\end{array}$ \\
\hline No. of cases & 29 & 14 & 10 & 62 & 30 & 25 & 33 & 10 & 21 & 7 & 9 \\
\hline Region & $\begin{array}{l}\text { South } \\
\text { Africa }\end{array}$ & Germany & Hong Kong & Brazil & $\begin{array}{l}\text { South } \\
\text { Africa }\end{array}$ & China & Tanzania & Italy & Scandinavia & Brazil & USA \\
\hline $\begin{array}{l}\text { Mean age } \\
\text { (years) }\end{array}$ & 21.3 & 26.5 & 36.9 & 27.9 & 31.3 & 28.8 & 26.1 & 32.7 & 35.1 & 25.4 & 26.6 \\
\hline Gender (M:F) & $1: 2.6$ & $1: 3.6$ & $1: 1.5$ & $1: 2.2$ & $1: 2.3$ & $1: 0.9$ & $1: 1.8$ & $1: 2.3$ & $1: 2$ & $1: 1.3$ & $1: 1.3$ \\
\hline Pain $(\%)$ & 31.0 & NA & 50 & 28.5 & NA & 23.0 & 28.5 & NA & NA & 0 & 0 \\
\hline Swelling (\%) & 58.6 & NA & 70 & 58.0 & NA & 100.0 & 30.0 & NA & NA & 100 & 44 \\
\hline $\begin{array}{l}\text { Site (Max: } \\
\text { Mand) }\end{array}$ & $1: 1.6$ & $1: 1.8$ & $1: 1.5$ & $1: 1.5$ & $1: 1.7$ & $1: 0.9$ & $1: 3$ & $1: 1.5$ & $1: 4.3$ & $1: 2.5$ & $1: 3.5$ \\
\hline $\begin{array}{l}\text { Shape } \\
\text { (unilocular: } \\
\text { multilocular) }\end{array}$ & $1: 2.2$ & $1: 0.3$ & 1:0.6 & $1: 1.7$ & $1: 4$ & $1: 2.2$ & $1: 4$ & $1: 1.5$ & $1: 1.1$ & $1: 0.7$ & $1: 1.6$ \\
\hline $\begin{array}{l}\text { Outline } \\
\text { (well-defined: } \\
\text { poorly defined) }\end{array}$ & $1: 0.2$ & NA & 1:0.6 & NA & 1:0.9 & $1: 0.8$ & NA & NA & $1: 1.1$ & 1:0.1 & $1: 1$ \\
\hline $\begin{array}{l}\text { Tooth } \\
\text { resorption } \\
\text { (\%) }\end{array}$ & 3.8 & 14.3 & 50 & NA & 43.0 & 13.0 & 52.4 & 20.0 & 19.0 & 0 & 11.1 \\
\hline $\begin{array}{l}\text { Tooth } \\
\text { displacement } \\
(\%)\end{array}$ & 76.9 & 57.1 & 80 & 19.3 & 73.0 & 47.8 & NA & 20.0 & 42.8 & 57.1 & NA \\
\hline
\end{tabular}

(20). The majority of tumours in this study sample were well-defined with variable degrees of cortication in both mandibular and maxillary lesions. Four ill-defined tumours were identified, three of which were located in the maxilla with all three lesions being unilocular in shape.

Additional features of myxomas may include displacement of adjacent teeth and close association with unerupted teeth. Tooth resorption is uncommon (1) but has been reported to occur in approximately half of myxoma cases by Simon et al. (8). Despite the extensive nature of the myxomas studied in this sample, only one (3.8\%) tumour caused tooth resorption, which is comparably low to all other reports as shown in Table 2. Noffke et al. (11) suggested that more frequent tooth resorption can be attributed to the large size of tumours; however, in this report, this was not the case. On the other hand, tooth displacement was most frequent when compared to all other reports (Table 2). The high frequency of tooth displacement confirms the slow growth rate of the tumour.

Reports in the literature account that maxillary tumours frequently extend to the maxillary sinus, especially at later stages $(2,14)$. Noffke et al. (11) reported that $(82 \%)$ of maxillary tumours showed expansion into the maxillary sinus. In the current study sample, six $(66.6 \%)$ of the maxillary tumours caused expansion of the maxillary sinus. This expansion into the maxillary sinus is unlike the balloon like expansion of ameloblastoma but is similar to that observed for fibrous dysplasia due to the infiltrative nature of the tumour. Expansion of the mandibular cortex was also noticed in $(77.7 \%)$ of mandibular myxomas. MacDonaldJankowski et al. (14) reported that (84\%) of cases showed buccolingual expansion.

Due to the variable presentation of odontogenic myxomas on conventional radiography, it may very difficult and inaccurate to make a diagnosis based on radiographic examination alone. These tumours may resemble ameloblastoma, aneurysmal bone cyst, intraosseous haemangioma, cherubism, central giant cell granuloma and odontogenic keratocyst. Some reports have also described that odontogenic myxomas can present with radiographic features similar to osteosarcoma (16). Hence, the possibility of malignancy should be considered and further investigations need to be employed, most common of which is a biopsy of the tumour.

Histopathological examination of deep incisional biopsy should be carried out to confirm the diagnosis of odontogenic myxoma. The lesion can be accessed through sockets of extracted mobile dentition or through sulcular incisions when dentition are present. Computed tomography can be used as a pre-surgical guide for biopsy taking in intrabony tumours by defining areas of infiltrated soft tissues and resorbed cortical bone.

Histological differential diagnosis of odontogenic myxoma should include metastatic Wilms' tumour with myxoid structures and myxomatous degeneration of neurofibroma. Central odontogenic fibroma and central odontogenic granular cell tumour must also be considered in the differential diagnosis (21).

The histological features of odontogenic myxoma have been comprehensively described in the literature yet there are numerous variations to its presentation. Odontogenic epithelial rests were rare and present in only two cases (6.9\%). This finding is similar to the range reported in the literature ranging between $8 \%$ and $20 \%(10,13,17)$. There are differing opinions on the role of these epithelial rests in the pathogenesis of odontogenic myxoma with some authors reporting on its role in the formation of myxoma cells, while other authors simply view them as 'residual rests' with no role in the pathogenesis of this lesion. Epithelium entrapment of neurovascular bundles has been described as a potential explanation for the presence of these epithelial rests (21). 
Residual bony trabeculae were present in $44.8 \%$ of cases. This finding is within the figures reported in the literature ranging between $25.8 \%$ and $56 \%(13,17)$. These bony trabeculae have been described to be accountable for the mixed appearance on radiographic images (11).

Advanced imaging modalities such as computed tomography and magnetic resonance imaging should be utilized in conjunction with conventional radiography as numerous reports have shown that they are of great diagnostic value $(22,23)$. Computed tomography has been shown to be of superior value to conventional radiographs, especially in demonstrating osseous and soft tissue involvement (24). Computed tomography along with magnetic resonance imaging can also be of great diagnostic value and aid in the surgical management of these tumours (25). More recently, Araki et al. (26) demonstrated that cone beam computed tomography may be very useful in identifying the internal structure and margins of odontogenic myxomas. These imaging modalities could not be included in this study due to the retrospective design of this study. In addition, very few patients had undergone these imaging techniques due to limited availability and high costs.

In conclusion, odontogenic myxomas have variable clinical, radiological and histological presentations which can be ambiguous leading to a misdiagnosis. Some of these features were similar to those of previous reports while others differed significantly. The mandatory use of conventional radiography along with histopathological examination and selective use of advanced imaging techniques will aid in arriving at an accurate diagnosis and proper identification of the tumour.

\section{References}

1. Langlais RP, Langland OE, Nortje CJ. Diagnostic imaging of the jaws, 1st edn. Baltimore: Williams and Wilkins, 1995; 916.

2. Jarmoc M, Shastri K, Hall JM. A clinico-pathologic correlation. Odontogenic myxoma. J Mass Dent Soc 2010; 59: 48-51.

3. Mosqueda-Taylor A, Ledesma-Montes C, Caballero-Sandoral S, Portilla-Robertson J, Godoy-Rivera L, Menenses-Garcia A. Odontogenic tumours in Mexico: a collaborative retrospective study of 349 cases. Oral Surg 1997; 84: 672-5.

4. Lu Y, Xuan M, Takata T, et al. Odontogenic tumours. A demographic study of 759 cases in a Chinese population. Oral Surg 1998; 86: 707-14.

5. Olgac V, Koseoglu BG, Aksakalli N. Odontogenic tumours in Istanbul: 527 cases. Br J Oral Maxillofac Surg 2006; 44: 3868.

6. Ladeinde AL, Ajayi OF, Ogunlewe MO, et al. Odontogenic tumors: a review of 319 cases in a Nigerian teaching hospital. Oral Surg Oral Med Oral Pathol Oral Radiol Endod 2005; 99: 191-5.

7. Adebayo ET, Ajike SO, Adekeye EO. A review of 318 odontogenic tumors in Kaduna, Nigeria. J Oral Maxillofac Surg 2005; 63: 811-9.

8. Simon EN, Merkx MA, Vuhahula E, Ngassapa D, Stoelinga PJ. Odontogenic myxoma: a clinicopathological study of 33 cases. Int J Oral Maxillofac Surg 2004; 33: 333-7.

9. Arotiba JT, Ogunbiyi JO, Obiechina AE. Odontogenic tumours: a 15-year review from Ibadan, Nigeria. Br J Oral Maxillofac Surg 1997; 35: 363-7.

10. Lo Muzio L, Nocinic PF, Favia G, Procaccini M, Mignogna MD. Odontogenic myxoma of the jaws: a clinical, radiologic, immunohistochemical and ultrastructural study. Oral Surg Oral Med Oral Pathol Oral Radiol Endod 1996; 82: 426-33.

11. Noffke CE, Raubenheimer EJ, Chabikuli NJ, Bouckaert MM. Odontogenic myxoma: review of the literature and report of 30 cases from South Africa. Oral Surg Oral Med Oral Pathol Oral Radiol Endod 2007; 104: 101-9.

12. Wachter BJ, Steinberg MJ, Darro DH, McGinn JD, Park AH. Odontogenic myxoma of the maxilla: a report of two pediatric cases. Int J Pediatric Otorhinolaryngol 2003; 67: 389-93.

13. Li TJ, Sun LS, Luo HY. Odontogenic myxoma: a clinicopathologic study of 25 cases. Arch Pathol Lab Med 2006; 130: 1799-806.

14. Macdonald-Jankowsky DS, Yeung R, Lee KM, Li TK. Odontogenic myxoma in the Hong Kong Chinese: clinico radiological presentation and systematic review. Dentomaxillofac Radiol 2002; 31: 71-83.

15. Kaffe I, Naor H, Buchner A. Clinical and radiological features of odontogenic myxoma of the jaws. Dentomaxillofac Radiol 1997; 72: 365-8.

16. Peltola J, Magnusson B, Happonen RP, Borrman H. Odontogenic myxoma - a radiographic study of 21 tumours. Br J Oral Maxillofac Surg 1994; 32: 298-302.

17. Martínez-Mata G, Mosqueda-Taylor A, Carlos-Bregni R, et al. Odontogenic myxoma: clinico-pathological, immunohistochemical and ultrastructural findings of a multicentric series. Oral Oncol 2008; 44: 601-7.

18. Friedrich RE, Scheuer HA, Fuhrmann A, Zustin J, Assaf AT. Radiographic findings of odontogenic myxomas on conventional radiographs. Anticancer Res 2012; 32: 2173-7.

19. Dezotti MSG, Azevedo LR, Fontão FNGK, Capelozza ALA, Sant'ana E. Odontogenic myxoma - a case report and clinicoradiographic study of seven tumors. J Contemp Dent Pract 2006; 1: 117-24.

20. White SC, Pharoah MJ. Oral radiology principles and interpretation, 5th edn. St. Louis: Mosby, 2004; 135-41.

21. Etemad-Moghadam S, Chookhachizadeh S, Baghaii F, Alaeddini M. Odontogenic myxoma: a study based on biopsy material over a 40-year period. J Contemp Dent Pract 2014; 15: 137-41.

22. Hisatomi M, Asaumi J, Konouchi H, Yanagi Y, Matsuzaki H, Kishi K. Comparison of radiographic and MRI features of a root-diverging odontogenic myxoma, with discussion of the differential diagnosis of lesions likely to move roots. Oral Dis 2003; 9: 152-7.

23. Macdonald-Jankowski DS, Yeung R, Li T, Lee KM. Computed tomography of odontogenic myxoma. Clin Radiol 2004; 59: $281-7$.

24. Koseki T, Kobayashi K, Hashimoto K, et al. Computed tomography of odontogenic myxoma. Dentomaxillofac Radiol 2003; 32: 160-5.

25. Cohen MA, Mendelsohn DB. CT and MR imaging of myxofibroma of the jaws. J Comput Assist Tomogr 1990; 14: $281-5$.

26. Araki M, Kameoka S, Mastumoto N, Komiyama K. Usefulness of cone beam computed tomography for odontogenic myxoma. Dentomaxillofac Radiol 2007; 36: 423-7.

\section{Acknowledgements}

The authors are grateful to the staff of the Department of Diagnostics and Radiology at the University of the Western Cape. No funding was required for the study.

\section{Conflict of interest statement}

No conflict of interests is declared by the authors. 